\title{
Review of contemporary computing technology to enhance breast imaging
}

\author{
Ray Cody Mayo* \\ Department of Diagnostic Radiology, The University of Texas, MD Anderson Cancer Center, USA
}

\section{Introduction}

Computers have revolutionized the field of diagnostic imaging and are absolutely essential in modern radiology practices [1]. First introduced into the radiology department in the 1960's, computers' role drastically expanded with the development of Radiology Information Systems (RIS). The earliest uses of computer technology related to imaging acquisition were nuclear medicine, digital subtraction angiography, computerized tomography (CT) in the 1970's, and magnetic resonance imaging (MRI) in the 1980's. The next major development was the picture archiving and communication systems (PACS). By the 2000's, many practices had converted to voice recognition software from transcriptionist. Also in the 2000's screening mammography computer aided detection (CAD) was reimbursed by insurance companies which precipitated its widespread adoption [2-4]. An area of current opportunity in the breast imaging world is the intersection several newly available technologies. Simultaneously, the American College of Radiology (ACR) has created a campaign to guide radiology called "Imaging 3.0." This program emphasizes the importance of adding value on behalf of all stakeholders including patients, hospital systems, and payers. Application of several new technologies may help achieve the goals of Imaging 3.0.

\section{The Cloud}

Cloud based computing is the process of using remotely located computer servers to store, process, and transmit data. Traditionally hospitals and radiology departments each maintained their own individual servers. In the breast imaging department there are several opportunities to improve performance using cloud computing. Mammography has been shown to reduce cancer mortality by up to approximately $40 \%$ [5-9]. Cancers detected with the aid of available comparison mammograms have more favorable characteristics than when prior exams are not available [10]. Comparison with previous examinations is associated with a significant decrease in the frequency of axillary node metastasis and the cancer stage for screening mammography ${ }^{11}$. These benefits are attributable to the ability to accurately detect subtle incremental mammographic changes which may otherwise be overlooked. Therefore, tremendous effort is expended to obtain prior images. Patients often have their exams located at multiple facilities in various geographic locations. Hospitals and outpatient imaging centers spend significant time and money tracking and compiling prior patient records, creating and mailing compact discs (CD), and importing images from discs into PACS results in substantial cost to the facility [12-14]. Additionally, approximately $30 \%$ unnecessary additional work per case is created when reports addendums are issues as prior outside exams become available and must be re-read [15].
A universally available cloud database is an attractive solution to solving the problem of access to old images. However, there are numerous other benefits. Reduced patient radiation doses will be realized since repeat images may be avoided. Additional radiation exposure is estimated at $1 \mathrm{mSv}$ per diagnostic mammogram [16]. When practicing the "As low as reasonably achievable" (ALARA) principle, available prior exams should be sought before repeating additional images. Also, a universal database is more economical than every hospital maintaining their own hardware with associated IT staff. This would be especially useful for practices that cover multiple locations and for patients that switch facilities. The cloud enhances interoperability for patients choosing to access to web-based portals for results and also allows increased access to their own imaging record. Cloud-based archiving also provides an efficient solution for the PACS requirement of a second-copy digital archiving.

\section{Artificial intelligence}

A neural network is a computer programing paradigm which enables a computer to learn from observational data. Deep learning refers to a powerful subset of machine learning techniques that detects patterns and creates learning within a neural network. The final product is a computer program that teaches itself how to learn from a tremendous amount of data which is provided to it. These technologies fall under the umbrella of artificial intelligence (AI). Importantly, the more data available to the program, the more data it has to learn from, and the more accurately it can perform.

This technology is currently being used to assist internet search results, voice recognition, and data analysis, but has not extended meaningfully into the medical imaging industry. Computer aided detection in the future will not involve teams of developers creating rules to help the computer find edges/pixels as in traditional CAD. Rather, a large amount of known data will be provided to a computer and software will learn to detect patterns. Currently available traditional CAD has led to no significant improvement in any performance metric, including sensitivity, specificity, positive predictive value, recall rate and benign biopsy rate [17].

However, there is much potential for the prospects of machine learning and neural networks. There are several possible applications of this technology. In addition to assisting with final diagnosis, another

Correspondence to: Ray C Mayo, Assistant Professor, Department of Diagnostic Radiology, The University of Texas MD Anderson Cancer Center, USA; Tel: +713-745-4555; E-mail: RCMayo@mdanderson.org

Received: October 27, 2017; Accepted: November 15, 2017; Published: November 18, 2017 
potential use would be AI algorithms that identify "quick negative" exams. This would be useful in high volume screening settings. If even $10 \%$ of the normal chest $\mathrm{x}$-rays, mammograms, and lung CT screens could be immediately identified as normal, a substantial amount of radiologist time and effort could be reallocated. A standardized report would be automatically generated for review and sign off. This concept is only viable if AI's performance could result in a sensitivity approaching $100 \%$. The concept of the "quick negative" would also be useful in underserved countries without easy access to local medical expertise.

\section{Cloud plus AI}

Although in concept these technologies have existed for some time, their proliferation is increasing its pace since huge amounts of data are now available in the correct format. The cloud and AI reinforce each other in a positive feedback loop. A cloud based image database could provide secure, patient-portable accessibility of prior exams for more accurate and timely interpretation of mammograms with objectively improved patient outcomes at reduced costs [18]. Also cloud based image database of normal and abnormal mammograms would be the ideal training resource to teach computers to find breast cancer using the current techniques of AI. Ultimately this concept is scalable to the entire radiology department as ideals of Imaging 3.0 are put into action [19].

\section{References}

1. Mixdorf MA, Goldsworthy RE (1996) A history of computers and computerized imaging. Radiol Technol 67: 291-296. [Crossref]

2. Freer TW, Ulissey MJ (2001) Screening mammography with computer-aided detection: prospective study of 12,860 patients in a community breast center. Radiology 220: 781786. [Crossref]

3. Morton MJ, Whaley DH, Brandt KR, Amrami KK (2006) Screening mammograms: interpretation with computer-aided detection--prospective evaluation. Radiology 239: 375-383.

4. Castellino RA (2005) Computer aided detection (CAD): an overview. Cancer Imaging 5: 17-19. [Crossref]

5. Fracheboud J, de Gelder R, Otto SJ (2009) National evaluation of breast cancer screening in the Netherlands 1990-2007. Rotterdam, the Netherlands: andelijk Evaluatie Team voor bevolkingsonderzoek naar Borstkanker.
6. Saadatmand S, Bretveld R, Siesling S, Tilanus-Linthorst M (2015) Influence of tumour stage at breast cancer detection on survival in modern times: population based study in 173797 patients. BMJ 351:4901.

7. Hendrick RE (2011) United States Preventive Services Task Force Screening Mammography Recommendations: Science Ignored. AJR Am J Roentgenol 196: 112116. [Crossref]

8. Otto SJ, Fracheboud J, Verbeek AL, Boer R, Reijerink-Verheij JC, et al. (2012) Mammography screening and risk of breast cancer death: a population-based casecontrol study. Cancer Epidemiol Biomarkers Prev 21: 66-73. [Crossref]

9. Webb ML, Cady B, Michaelson JS, Bush DM, Calvillo KZ, et al. (2014) A failure analysis of invasive breast cancer: Most deaths from disease occur in women not regularly screened. Cancer 120:2839-2846. [Crossref]

10. Frankel SD, Sickles EA, Curpen BN, Sollitto RA, Ominsky SH, et al. (1995) Initia versus subsequent screening mammography: comparison of findings and their prognostic significance. AJR 164: 1107-1109.

11. Hubbard RA, Kerlikowske K, Flowers CI, Yankaskas BC, Zhu W, et al. (2011) Cumulative probability of false-positive recall or biopsy recommendation after 10 years of screening mammography: a cohort study. Ann Intern Med 155: 481-492. [Crossref]

12. Kleit AN, Ruiz JF (2003) False positive mammograms and detection controlled estimation. Health Serv Res 38: 1207-1228. [Crossref]

13. Bassett LW, Shayestehfar B, Hirbawi I (1994) Obtaining previous mammograms for comparison: usefulness and costs. AJR Am J Roentgenol 163: 1083-1086. [Crossref]

14. Wilson TE, Nijhawan VK, Helvie MA (1996) Normal mammograms and the practice of obtaining previous mammograms: usefulness and costs. Radiology 198: 661-663. [Crossref]

15. Poplack SP, Carney PA, Weiss JE, Titus-Ernstoff L, Goodrich ME, et al. (2005) Screening mammography: costs and use of screening-related services. Radiology 234: 79-85. [Crossref]

16. Boone JM (2013) Radiation Dose Levels in the Diagnostic Examination. Society of Breast Imaging News, Winter.

17. Fenton JJ, Taplin SH, Carney PA, Abraham L, Sickles EA, et al. (2007) Influence of computer-aided detection on performance of screening mammography. $N$ Engl $J$ Med 356: 1399-1409. [Crossref]

18. Mayo RC 3rd1, Pearson KL, Avrin DE, Leung JW (2017) The Economic and Social Value of an Image Exchange Network: A Case for the Cloud. $J$ Am Coll Radiol 14: 130-134. [Crossref]

19. Mayo RC, Parikh JR (2016) Breast Imaging 3.0: The Face of Imaging 3.0. J Am Coll Radiol 13: 1003-1007. [Crossref]

Copyright: $\odot 2017$ Mayo RC. This is an open-access article distributed under the terms of the Creative Commons Attribution License, which permits unrestricted use, distribution, and reproduction in any medium, provided the original author and source are credited. 